\title{
A Study of Form and Content of Private Speech Used by Iranian EFL Learners
}

\author{
Ehsan Alijanian \\ English Department, Faculty of Foreign Languages, University of Isfahan, Iran \\ Saeed Ketabi \\ English Department, Faculty of Foreign Languages, University of Isfahan, Iran \\ Ahmad Moinzadeh \\ English Department, Faculty of Foreign Languages, University of Isfahan, Iran
}

\begin{abstract}
From the sociocultural point of view, the investigation of private speech is important in seeing how the mind works. Yet, not much is known about the form and content of private speech. A group of English language learners were required to talk about some topics of their reading courses. Their voices were recorded and the private speech used by them were identified. It was found that the main role of the loud and silent forms of the private speech in the data is to help learners manage the interaction. Private speech is embedded within the speech context and it needs to be explained in the context in which it happens.
\end{abstract}

Index Terms - private speech, sociocultural theory, interaction

\section{INTRODUCTION}

Conventionally, the study of SLA has centered on learners' use of speech for social or public purposes (as in writing for an audience or taking part in conversation) (Deguerrero, 2012). Recently, however, a growing number of scholars have begun to identify the prominence of speech that L2 learners direct to themselves. Speech that is self-directed and intended for adjusting oneself is identified as private speech (Deguerrero, 2012).

Investigation of private speech has been significantly influenced by Vygotsky's (1986) theories of cognitive advancement. Mainly attractive has been his famous suggestion that children make available speech through a process of internalization that contains a development from social speech to inner speech, with an intermediate phase he called egocentric speech (Deguerrero, 2012). At this phase, speech stops to be totally social and takes on a psychological aspect. Speech begins to serve the intellect and help the child in problem-solving, imaginary play, controlling behavior, and other cognitive procedures. A preschool child, working alone and seeking to resolve an animal home matching task. Egocentric speech is articulated and can be received by others (or seized by a tape recorder), but it is self-directed (Deguerrero, 2012). Egocentric speech does not stay outward, nonetheless. At some time, Vygotsky postulated, it goes secret as silent inner speech. For of its prominence in mental and linguistic improvement, the stage of egocentric speech - more frequently denoted to as private speech in existing literature- has created great interest as a central window into language learning and use, both from a first language (L1) and an L2 standpoint (Deguerrero, 2012).

In L2 learning, private speech has been examined mostly from two viewpoints: (1) as an indication of language learning in progression, and (2) as a self-regulatory means of getting influence in mental tasks. Both standpoints have revealed extensive practice of private speech among L2 learners of all ages, language backgrounds, and proficiency stages (Deguerrero, 2012). A number of studies have been purposefully inaugurated to provoke private speech (McCafferty, 1994); other investigations have given proof of incidental private speech among L2 students (see, for example, Saville-Troike (2006)). A large number of investigations have celebrated oral private speech as it happens in private or cooperative discourse; some research has observed private speech as it is revealed in writing and gesture (Deguerrero, 2012). Roebuck (2000), for instance, found private speech features - such as lexical word searches - in the written protocols of college learners of Spanish, whereas Negueruela et al., (2004) noticed semantic features associated with L1 thinking in some of the gestures of advanced ESL students. Deguerrero (2012) contends Private speech between L2 students has been described in the literature as happening both impulsively in normal classroom contexts (e.g., Ohta, 2001) and in experimental settings purposefully shaped for research purposes (e.g., Centeno-Cortes \& Jimenez, 2004).

Private speech between L2 learners has been illustrated to hold an important part in language acquisition. In Vygotskyan sociocultural theory, this is identified as the internalizing use of private speech so that private speech is identified as a beneficial instrument for turning inwards L2 resources in the milieu (Deguerrero, 2012).

Form of Private Speech 
Form signifies prosodic and structural features of private speech. Conventionally, research on private speech has taken into account volume, intonations, and abbreviations to recognize the form of private speech. Likewise, two common features surface among earlier studies on adult language learners: (a) silent speech/whispering), and (b) loud utterances that are directed to the self (self-directed utterances such as self-directed questions, comments, and responses to the self) (DiCamilla \& Anton; 2004).

Silent speech/whispering. Most studies recounted private speech to happen in a low tone of voice (Platt \& Brooks, 2002). Studies verified that learners whispered to themselves to (a) gain regulation (Brooks et al., 1997); (b) to be involved cognitively in the task (Brooks et al., 1997); (c) to retrieve knowledge of L2 from memory (Platt \& Brooks, 2002); and (d) to adapt themselves and their partners to the task (DiCamilla \& Anton, 2004).

Brooks et al. (1997) studied Spanish learner statements during a collaborative jigsaw activity and recounted that students whispered to themselves in order to achieve regulation and for cognitive engagement to the task. They conveyed that their learners whisper target language in L2 (Spanish) like counting in the L2 ("Uno, dos, tres, cuatro, cinco"), making affective reactions ("Oh goodness," "Damn this is hard"), and opening or closing an activity ("Let's see here...", "Okay..." "Now what?") (Khorshidi \& Abdikhah, 2013). In the same way, DiCamilla and Anton (2004) examined Spanish learners with changing proficiency levels during a cooperative writing task to recognize clear instances of private speech in adult collaborative interaction. They identified cases of self-whispering during the activities. They maintain that Spanish learners whispered to themselves when they are trying to retrieve knowledge of the target language form in Spanish with the help of repetitions.

Loud forms of private speech. These utterances are created in the social tone of voice but they do not have social speech qualities. These are private speech utterances that seem like social speech. These are called private speech since they are not addressed to the interlocutor but to the self. Earlier studies advocate that private speech is situated in context and it could not be in a specific pre-defined form when adult language learners are involved in cooperative interaction, when associated with individual activities of the learners. For instance, the frontiers between private and social speech may obscure in a conversation between two learners during a collaborative language activity.

A few researchers directly examined private speech in adult language learner collaborative interaction (DiCamilla \& Anton, 2004) and others recounted existence of private speech in related studies on cooperative learner discourse (Brooks \& Donato, 1994). These researchers studied all utterances to have a psychological and social orientation and they concentrated on the regulatory functions of the utterances when studying private speech (DiCamilla \& Anton, 2004).

\section{Contents and functions of private speech}

Inquiries on adult learner private speech do not clearly categorize content of private speech but it is conceivable to classify content in studies on private speech. These classifications help categorize the content referred to in SLA research on adult private speech. A review of literature since the late 1980's shows that the content of adult learner private speech incorporated but not limited to self-directed questions, affective markers, repetitions, utterances that indicate the hypothetical stance of the speaker, labeling or counting some aspects of the task, pause fillers, metalanguage, and comments on one's own task, knowledge, and performance.

It is key to bear in mind that private speech is set in the context in which it happens. As documented earlier, private speech may occur in diverse forms and the contents may not be limited to the ones listed below. These classifications are not exclusive, for instance, a self-directed question can also be metalanguage. One of the research questions in this study tries to ascertain the relationship between the form, content, and function of private speech of adult language learners in a cooperative discourse context. The content categories and their functions are explained below.

Based on what has been discussed the following research question will be addressed in this study: What are the forms and functions of private speech used by Iranian EFL learners?

\section{METHODOLOGY}

Thorough examination of the interaction seems critical for the clarification of the results of the specific context of this study. Participants in this research are advanced English language learners. Learners were required to talk about some topics that they had already encountered in their reading courses. While they were involved in the cooperation their speech was audio recorded. This stimulating task as a plan that is contributing to considerable collaborative talk is what is needed in this study in investigating the language. By analyzing the language produced by learners the private speech used by them is analyzed.

Data coding for the form and content of private speech are described below.

\begin{tabular}{|l|l|}
\hline Form & Definition \\
\hline Silent & Utterances that are made in ancerning the low tone of voice. \\
\hline Loud & These utterances are not generated in the silent form but they are addressed to the self. \\
\hline
\end{tabular}

\section{Silent speech/whispers.}

A: well, How can I say it? ... It's a home appliance that is quite modern.

B: Ok.

A: As I remember in the past in the homes we did not have such an instrument. 
B: Where in the home is it used?

\section{Loud forms}

A: You know, the word I am explaining to you shows a typical kind of person who is different from others. We have an example of a Turkish computer programmer who has made billions of dollars with designing hardware and software.

B: Wow, great. Can you explain more?

Content

1. Self-directed questions

2. Affective Utterances

3. Repetitions

Comments that Indicate a

4. hypothetical stance

5. Labels

6. Pause fillers

7. Metalanguage:

8. Comments on self

\section{Description}

Statements involved questions addressed to the self. The question is either disregarded by other

students or the individual answers to it himself/herself immediately after the question.

Any statement that displays affective expressions of the speaker concerning the task or performance on the task for emotional release, in order to motivate the self.

Repetitive statements or sounds as if the individual is looking for a word, correcting a previous speech, or focusing attention on the task.

Contain verbs, adverbs, and modal verbs such as "think, guess, believe, probably, can, could, will, would". These utterances may help the student to orient his/her interlocutors to the task. Any type of labeling, and counting to bring structure to a text. Participants may also use these statements to mark the beginning and end of an activity or episode. These statements may be employed to bring structure to the task, or to manage the task by labeling, naming, or counting. Any type of statement that seem to be comprised of meaningless sounds such as eh, um, ah, er, etc. but that indicate a thinking process. They may show that the learner is concentrating or planning his next utterances.

Any type of statement that is utilized to analyze or describe language. These utterances can contain individual's own comments about the language, and its structures and use.

These are utterances that learners make to create shared cognition and regulation. These private speech utterances usually occur either before or after a turn and play an important role in establishing shared orientation.

\section{Self-directed questions.}

A: Everyone by using this word thinks of a word that I can't use it now and is used in carpentry. Can you guess?

B: Please explain more.

A: What was it? A tool. It's a tool for attaching two pieces of wood.

B: A nail?

Affective markers.

A: This word is used when two countries for example are in state of battle conflict. If this thing is used huge number of people will be killed.

B: Oh my God ... Is this nuclear bomb?

\section{Repetitions.}

A: If you are homesick, the way you feel is the word I want.

B: I am homesick, I am homesick. Tired?

A: Close, it's close to nervousness.

\section{Comments that indicate a hypothetical stance.}

A: In the case of horror movies we sometimes have a group of people who suddenly enter ships.

B: They may attack the ship. Do they try to steal people's belongings?

\section{Labeling and counting.}

A: The substance I am explaining to you is used in cooking without this food is tasteless.

B: Oil?

A: Oil is added before this substance.

B: First oil, then another substance. Is it water?

A: No, it's used during cooking.

\section{Pause fillers.}

A: When you do a good job people clap for you and express their ... can you guess?

$\mathrm{B}$ : hmmm, eeh, is the word pleasure?

\section{Metalanguage.}

A: I am explaining a verb to you which shows a shocking and horrible sound that makes people afraid.

$\mathrm{B}$ : A verb frightening people. And do people run away?

\section{Comments on self.}

A: The word I am explaining to you is a kind of taste which is not pleasant.

B: Is it salty?

A: No ... It's difficult to explain, rotten food or vegetable have such a taste.

\section{RESULTS}

In this next example silent private speech is observed as repetitions when the learner focuses attention on the task:

A: the word shows a typical kind of person different from others.

$\mathrm{B}$ : A different kind of person, a different kind of person. 
In the following example we see A's silent private speech in line 2 notifying B and initiating his assistance. Again in line 3 A utters another private speech showing his frustration and this causes B to again help his by asking about the function of the word.

1 A: Well, How can I say this word?

2 B: do your best.

3 A: Hmmmm ...

$4 \mathrm{~B}$ : Is it a verb?

There are also instances that silent private speech is uttered in an incomplete form.

A: when people are traveling they use this item for example.

$\mathrm{B}$ : people traveling.

A: ok. How can I? ... This is a compound word consisting of a noun and an adjective.

Findings for content and functions of private speech

Affective markers.

Affective marker showing disappointment of being incapable to finish the task

A: When we go to a foreign country we have such a feeling.

B: piish.

Affective marker specifying indications of finding

A: For example if someone has a successful lecture people ... for him.

B: oooh ... clap?

A: Yes.

Hypothetical stance.

1 A: This word is used in time you don't think someone is correct.

2 B: Rectify?

3 A: No, I should explain differently ...

4 B: You mean we disagree with someone.

In the excerpt above, $\mathrm{B}$ is using private speech in line 3 to clearly revise his task strategies and bearing in mind different options at the end of the task. This statement shows hypothesizing and reasoning and as a result, it facilitates B to achieve self-regulation to adapt towards interaction. It can be stated that hypothetical stance statements show students' revision of their approach towards the language activity in order to have regulation.

Labeling/Counting.

In this example, the learner adjusts self and peer to the task in a collaborative activity.

A: Well, this part 1,2,3,4 lines. Ok, let me explain this.

Repetitions.

A: I know what you're talking about okay okay okay okay ... .

A: Other other other symptoms.

In the examples above repetitions facilitate retrieving vocabulary.

Pause fillers.

In the next except A sees the word before explaining the word to his partner. She says that she is not prepared and carries on to review the words while humming. His humming shows that she is still planning and organizing his thoughts for the task and indicates his peer not to distract his until he is done with planning as a tactic to evade distraction.

A: Go.

B: let's wait. Dm dm dm.

Metalanguage.

In the example below B says "a verb" to himself, while searching his memory in order to find the word explained by his peer.

A: This word is used when you don't want to show your real feeling. It's a noun.

B: Fake affection you mean? And a noun?

Self-directed questions.

This example is the lexical search of the learner.

A: What was that word? Sister-in-law

Comments on self.

A: How can that happen? Can you explain about this concept?

By using comments on self, the participants intentionally reveal their thought processes by showing the limits of their knowledge.

\section{DISCUSSION AND CONCLUSION}

Some hypothetical clauses, self-directed questions, and comments on self also occur largely in the loud form and may get reactions from peers. The main role of the loud and silent forms of the private speech in the data is to help learners manage the interaction. By expressing their thoughts, learners tried to concentrate on the activity by attempting to 
organize their cognitive processes. As a case, learners used repetition to regulate their thoughts in realizing the vocabulary. Furthermore, learners frequently used loud private speech to encourage themselves and arrange their thoughts while they tried to coordinate their following move.

Private speech utterances are utilized as a mental means that is adjusted to the participant's peer. Nonetheless, there are variations in how learners use it as a cognitive tool. For instance, a number of students use affective markers to get scaffolding from their peers. Repetitions are sometimes used to manage thought and sometimes for lexical pursuit and sometimes as a mental strategy to raise the awareness of peers on a difficult task. Some participants adjust metalanguage to their peers and use incorrect syntax so as to give strategic assistance and maintain interaction (when peered with less proficient partners) and at times they utilize correct forms of the language.

In the current study, participants have a high awareness of self and other knowledge and they constantly examine assumptions about peers' awareness and functioning. It was observed that students utilize hypothetical clauses purposefully to orient their associates to the task and to search for ways out of difficulties by giving ideas. Swain (2000) contends that the use of metalanguage is very much governed by the context. In this study correct use of the language is not taken into account as the task goal so there are many times language is used with grammatical mistakes since participants only want to communicate. Participants' abilities use the rules about the structure of their L2 in a unique way indicate their control over the language.

Metalanguage use is known to be task-dependent (Swain, 2000). It is possible that the type of task elicits a particular type of metalanguage from learners. In this study, learners' goals participating in the task are not language learning or correct use of language forms but simply communicating a concept to peers in a social setting. Therefore, it is possible that peers do not feel the pressure to use correct references to the grammatical structure of the language. Instead, they focus on communicating the message in the most effective way in light of the task's time constraints.

In short, the study of private speech among L2 learners seems to be a productive and encouraging opportunities of topics in L2 acquisition; Private speech offers teachers and researchers significant evidences into features of L2 language learning and use that can not be observed but are nonetheless crucial (De Guerrero, 2012).

As a self-regulatory mechanism, private speech has also welcomed substantial attention among L2 researchers (McCafferty, 1994). Students who are skillful to carry out psychological processes can use private speech, an earlier mode of thinking, to obtain self-regulation in instants of mental struggle (De Guerrero, 2012). A possible description for the use of private speech can be that the clear makeup of vocalized private speech aids solidify sensible consideration by maintaining awareness concentrated (De Guerrero, 2012). Findings concerning L2 and FL learners do indicate that they now and again express their rational procedures through the medium of private speech after resolving demanding scholarly tasks that need use of the L2 (De Guerrero, 2012).

From the sociocultural theoretical framework, language development instigates at the social plane and moves towards the psychological plane in the process of learners becoming self-regulated. However, only a limited number of investigations have considered adult language learner private speech in interaction. Lantolf (2009) argues that various groups of students should be examined in different contexts in order to enlarge the SLA database and to understand learner's use of private speech in experimental context on cooperative tasks.

As described above, private speech is embedded within the speech context and it needs to be explained in the context in which it happens. According to Frawley and Lantolf (1984), private speech works as a cognitive tool in the internalization of L2 where its function is to express the thinking process and to mediate thinking and learning in language learners' efforts to achieve regulation over tasks and activities.

\section{REFERENCES}

[1] Brooks, F. B., \& Donato, R. (1994). Vygotskyan approaches to understanding foreign language learner discourse during communicative tasks. Hispania, 77, 261-274.

[2] Brooks, F. B., Donato, R., \& McGlone, V. (1997). When are they going to say it right? Understanding learner talk during pair work activity. Foreign Language Annals, 30(4), 524-541.

[3] Centeno-Cortes, B., \& Jimenez (2004). Problem-solving tasks in a foreign language: The importance of the L1 in private verbal thinking. International Journal of Applied Linguistics, 14(1), 7-35.

[4] De Guerrero, M. (2012). Private Speech in Second Language Acquisition. The encyclopedia of applied linguistics.

[5] DiCamilla, F.J., \& Anton, M. (2004). Private speech: A study of language for thought in the collaborative interaction of language learners. International Journal of Applied Linguistics, 14(1), 36-69.

[6] Donato, R. (1994). Collective scaffolding in second language learning. In J. P. Lantolf \& G. Appel (Eds.), Vygotskian approaches to second language research (pp. 33-56). Norwood, NJ: Ablex.

[7] Frawley, W., \& Lantolf, J. P. (1984). Speaking and self- disorder: A critique of orthodox L2 research. SSLA, 6, 143-159.

[8] Khorshidi, A., \& Abdikhah, S. (2013). A study of the form and content of private speech produced by Iranian adult EFL learners. Theory and practice in Language Studies, 3(5), 836- 845.

[9] Lantolf, J. P. (2009). Second language learning as a mediated process. Language Teaching, 33, 79-96.

[10] McCafferty (1994). Adult second language learners' use of private speech: A review of studies. The Modern Language Journal, 78(4), 421-436.

[11] Negueruela, E., Lantolf, J.P., Jordan, S.F., \& Gelabert, J. (2004). The private function of gesture in second language speaking activity: A study of motion verbs and gesturing in English and Spanish. International Journal of Applied Linguistics, 14, 113147.) 
[12] Ohta, A. S. (2001). From acknowledgment to alignment: A longitudinal study of the development of expression of alignment by classroom learners of Japanese. In G. Kasper and K. Rose (Eds.), Pragmatics in language teaching (pp. 103-120). Cambridge: Cambridge University Press.

[13] Platt, E. J. and Brooks, F. B. (2002) Task engagement: A turning point in foreign language development. Language Learning 52 (2): 365-400.

[14] Roebuck, R. (2000). Subjects speak out: How learners position themselves in a psycholinguistics task. In J. P. Lantolf (Ed.), Sociocultural theory and second language learning. Oxford: Oxford University Press.

[15] Saville-Troike, M. (2006). Introducing Second Language Acquisition. Cambridge: Cambridge University Press.

[16] Swain, M. (2000). The output hypothesis and beyond: Mediating acquisition through collaborative dialogue. In J. Lantolf (Ed.), Sociocultural theory and second language learning (pp. 97-114). Oxford: Oxford University Press.

[17] Vygotsky, L (1986). Thought and language. Boston: MIT Press.

Ehsan Alijanian teaches linguistic and teaching courses in different universities and institutes of higher education. His research interests encompass cognitive and sociocultural linguistics, sociolinguistics, discourse analysis and pragmatics. His current research focuses on sociocultural linguistics, specifically on_the construct of language related episodes during collaborative tasks.

Saeed Ketabi has published papers in different journals including Reading Psychology, Innovation in Language Learning and Teaching, Teaching English Language, Psycholinguistic Research, Translation and Interpreting Studies, Psychological Studies, and Advanced Studies in Humanities and Social Science.

Ahmad Moeinzadeh is an associate professor of ELT in the department of English Language and Linguistics in the University of Isfahan. He has supervised many dissertations across a wide range of topics, including syntax, morphology, language acquisition and learning. 